Reviews

1996; Vincentnathan and Vincentnathan 1994). Changes and improvements in the economy have especially diminished dependence on caste hierarchy; increased involvement of people in new occupations; reduced interaction with caste members; and dispersed people away from their home villages. I would suggest that as the frequent interactive relationships that the traditional occupations provided declined, and the new occupations promoted separation, individualism, and alienation from each other, the community withered away and so did its panchayat.

\title{
References Cited:
}

Baxi, Upendra, and Marc Galanter.

1979. Panchayat Justice: an Indian experiment in legal access. In M. Cappellett and B. Barth (eds.), Access to Justice Volume III: Emerging Issues and Perspectives. Pp. 341-386. Milan: Sijthoff andNoordhoff-Alphenaandenrijn.

Cohn, Bernard.

1965. Anthropological notes on disputes and law in India. American Anthropologist 67(6):82-122.

Durkheim, Emile.

1915. The Elementary Forms of Religious Life. J. W. Swain (trans.). London: George Allen \& Unwin, Ltd.

Moore, Erin.

1985. Conflict and Compromise: Justice in an Indian Village. Monograph Series No. 26. Lanham, MD: University Press of America.

Nader, Laura.

1969. Law in Culture and Society. Chicago: Aldine Publishing Company.

Srinivas, M. N.

1989. The Cohesive Role of Sanskritization and Other Essays. Delhi: Oxford University Press.

Vincentnathan, S. George.

1992. Social construction of order and disorder and their outcomes in two South Indian communities. Journal of Legal Pluralism 32:65-102,1992.

1996. Caste politics, violence, and the panchayat in a South Indian community. Comparative Studies in Society and History 38(3):484-509.

Vincentnathan, S. George, and Lynn Vincentnathan.

1994. Untouchable themes of equality and hierarchy in intergenerational relations and conflict resolution. Journal of Cross-Cultural Gerontology 9(1): 1-19.

\section{Questioning Geopolitics: Political Projects in a Changing World System, Edited by Georgi M. Deruglian and Scott L. Greer. Westport, CT: Praeger Publishers (2000), 264 pp.}

\section{Reviewed by Douglas Keare, Lincoln Institute, Cambridge, MA.}

This collection of essays aims to find regularity and predictability in a changing world geopolitical system and, frankly, falls far short of its mark. There are at least three features of this particular book that "put me off": its too liberal reliance on jargon; its apparent preoccupation with a "contemporary global crisis" that I was not aware existed; and its underdeveloped editorial organization. The problem of having to try to deal with a jargon with which, as an economist, I was totally unfamiliar - and the overuse of arcane words (the more arcane the better, apparently) - is a minor quibble. My other two concerns are not, for they affect the question of whether this is in fact a book, as opposed to a printing between covers of thirteen essentially unrelated essays.

There is a sense running through the book - which was written well before 11 September 2001 - that we were somehow in the throes of a "contemporary global crisis." This would, I think have been news of a rather surprising sort to the majority of the world's population who, at the time didn't even know if we were in or moving into a first recession in over a decade. To be sure, a motley group of protesters had been doing their level best to disrupt meetings having to do with the international economy for the past couple of years, most people were vaguely aware of potentially escalating threats from terrorists, and we confronted the familiar set of problems; but a global crisis? What were the authors and/or editors thinking about? And how broad a coterie of political scientists and other social scientists concerned with geopolitics and world-systems shared their opinion(s)? 
Reviews

I have not encountered an even remotely satisfying answer to these questions in the book or in my ruminations about it; and perhaps the failure is mine. There is a sense in a couple only of the papers that the contributors are referring to the "chute" of the East Asian economies in mid-1997 (not 1998). But this can't be a crisis - not to mention a global one. The countries themselves are not even concerned enough that they have attacked twenty percent of the agenda of bad policies and practices that will continue to plague them; and the countries, taken together, are not at all important enough economically to have a determining effect, in any direction, on the course of the international economy. What is a quite important issue emanating from an Asian economy is that Japan, so recently a major engine of growth and universal candidate to become the "hegemon" of the 21 st Century (two factors mentioned by the authors), has been stuck in the economic doldrums for over a decade, but has taken few corrective actions and shows no signs of getting out any time soon. This is a serious proposition - if not exactly a crisis - for world-systems and world welfare. But, as Japan is a (very highly) developed country, the authors do not exhibit concern.

Beyond this, it is difficult to imagine the considerations that gave rise to this extremely loosely integrated book. Its section titles provide clues ("Restructuring World Power," "Redefining World Culture," "From National States to Regional Networks"), although they are not supported in the progression of their papers. And these clues are pretty much obliterated by reading the Introduction, which, besides being besotted with the concept of hegemony, is devoted to this and a couple of other themes/concepts that are scarcely picked up by the component papers. The introductory essay does offer rough guidance on its final page, but, until I had ploughed through the first two papers of Part I to little avail ("Globalizing Capital and Political Agency in the 21st Century," by Stephen Gill, and "Stateness and System in the Global Structure of Trade: A Network Approach to Assessing Nation Status," by Michael Alan Sacks, Marc Ventrisca, and Brian Uzzi), I did not return to the Introduction and Table of Contents to see if I had missed the roadmap or hints thereof.

I found that I had missed the hints, and that the book's papers should have been rearranged to go from the general to the more particular cases. This would have given a logical sequence to the principal themes of the component papers, though it doesn't seem to sustain the intended structuring of the first two Sections. The present introduction would have to have been largely reconceived to served to introduce this flow of ideas; and perhaps its authors could have, in addition, constructed a paper to rebut in some measure the principal argument of the last paper in the book's first section, Collins and Waller's "Predictions of Geopolitical Theory and the Modern WorldSystem. And in a final organizational suggestion, the book would have benefited from a concluding chapter, on which more below.

I am oversimplifying, though one must do so within the constraints of a Review, to point out that, thus reorganized and depending principally on the papers of Collins and Waller (fortunately not Wallerstein, who apparently sowed the main seeds of the book's confusion a generation hence), Chirot ("Why Must There Be a Last Cycle? The Prognosis for the World Capitalist System and a Prescription for Its Diagnosis") and Chen ("The Geoeconomic Reconfiguration of the State: The Asian-Pacific Transborder Subregions in the World System"), the principal messages of the book are as follows:

(1) "The notion of world-system hegemon (should) be deconstructed" (Collins and Waller, p. 59).

(2) The term "modernization" should be resurrected from the disrepute into which it was thrown by readers of Wallerstein some 25 years ago (Chirot, p. 69).

And,

(3) In order to understand better how regional networks (trade and other) may interact and perhaps conflict with globalization, it is vital to look at the role of transborder regions.

So much for world-system theory.

Facetiousness aside, it really does seem that the search for regularity and predictability in the changes in world geopolitical systems - at least as this has been described in the Introduction and component papers - has gone off the tracks, maybe even from the start. A particular clue to this is in the discussion(s) of long economic cycles or waves (Kondratiev cycles) in Derluguian and Goldfrank (p. 7) Chirot (p. 81) and elsewhere. This becomes particularly clear when Chirot observes, in error, that " the only noted recent economic historian to have taken long cycles seriously is Walt Rostow" Has he never heard of W. Arthur Lewis, the Nobel laureate? More to the point, though economists do indeed take cycles seriously - inventory (or business) cycles and, yes, long cycles too - they do not, apart from infrequent exceptions, such as Rostow, do so deterministically. Perhaps this is a caution worldsystems analysts should take to heart in seeking to restructure their study of world power relationships.

I wonder, too, whether a bit of a change of heart - or at least perspective - might not also serve them well. It might be too much to hope, but, in addition to the restructuring of this book suggested above, I would very much like to have seen at the end a couple of papers devoted to alternatives to the approach taken by Thomas L. Friedman 
Reviews

to much the same set of issues examined in this set of papers in The Lexus and the Olive Tree (Farrar, Strauss, Giroux 2000). While I freely admit to preferring an evolutionary approach, à la Friedman, to addressing the principal problem behind the concerns of the authors in this book - that today's democratic processes are woefully too slow in recognizing and dealing with the socio-economic and other "injustices" prevailing in a "globalizing" market economy - I don't insist upon being gratified on this point. Still it seems that those persuaded that only revolutionary approaches will do the trick, might do well to set a conscientious effort such as Friedman' as their counterfactual, rather than the caricatures they habitually use as, apparently in this case.

\section{People and Forests: Communities, Institutions, and Governance, edited by Clark C. Gibson, Margaret A. McKean, and Elinor Ostrom. Cambridge, MA: MIT Press (2000), xxiv, 274 pp.}

\section{Reviewed by Stacy Rosenberg, Environmental Science, Studies, and Policy Program/ Department of Geography, University of Oregon.}

This edited volume investigates the significant relationship between forest users, local institutions, and forest conditions. The International Forestry Resources and Institutions (IFRI) research program provides the framework for the empirical studies included in this volume, and the systematic and micro-level analysis utilized by the IFRI protocol produces valuable comparative data on the important role that local-level institutions play in forest use and condition. Each chapter draws on the principles and interdisciplinary approach of the IFRI program, and uses case studies from India, Uganda, Nepal, Ecuador, and Bolivia. The integration of social and biophysical science research methods is an effective approach to understanding the complex relationship between forest users, local institutions, and forest conditions. Each chapter is well written and provides a thorough description of institutional, socioeconomic and biophysical factors that influence human incentives and behavior that have consequential impact on local forest conditions. This volume provides a sophisticated overview of the successful attributes of common property regimes, with a focus on local-level forest management. It summarizes and further expands earlier common property research efforts, and contributes significantly to the common property literature.

In Chapter One, Clark C. Gibson, Margaret A. McKean, and Elinor Ostrom emphasize the critical role that local communities play in forest management. Case studies are highlighted and the benefits of micro-level, comparative analyses are discussed. Margaret A. McKean in Chapter Two defines relevant terms utilized in common property literature in a very concise and clear manner. Her description of common pool resources, common property regimes, and the distinction between goods, rights, and owners is a valuable contribution to this volume. The overview of common property regimes and the attributes of successful regimes are comprehensive and provide a strong foundation for the case studies that follow this chapter.

Arun Agrawal argues in Chapter Three that forest council size is an important factor in determining the success of collective action to protect forest resources. His study of nine forest councils in Kumaon Himalaya, India shows that very small councils were disadvantaged due to limited resources, while moderate-sized councils had greater resources that enabled them to better protect forest areas through effective monitoring and enforcement activities. In Chapter Four, Abwoli Y. Banana and William Gombya-Ssembajjwe compare five forests in Uganda and find that security of tenure and the level of rule enforcement for each forest accounted for variation of forest conditions. High levels of illegal consumptive activities occurred in three forest reserves, while limited illegal activities were found in the other two forests. Secure tenure regimes and effective rule enforcement were determined to be significant factors in preventing forest degradation.

In Chapter Five, Charles M. Schweik analyzes the spatial variation of the Sal tree in southern Nepal and findss that optimal foraging patterns are impacted by institutional and social factors. The importance of integrating social and biophysical research methods was a critical element in this study, and human behavior, slope steepness, elevation, and east-west location of forest plots were significant factors in determining the geographic variation of forest conditions. In Chapter Six, Clark C. Gibson and C. Dustin Becker demonstrate that comuna members in western Ecuador utilized different parts of a forest depending on property rights. The portion of the comuna forest not allocated to individuals had been seriously degraded, while allocated plots have had less exploitation. While variation did exist in the allocated plots, overall this part of the forest is in much better condition than the unallocated portion. 